\title{
Prognostic value of miR-339-5p in patients with prostate cancer and its effects on tumor progression
}

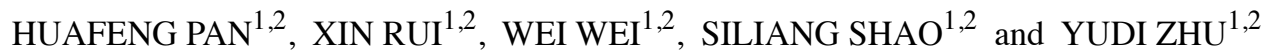 \\ ${ }^{1}$ Department of Urology, Hwa Mei Hospital, University of Chinese Academy of Sciences, Ningbo, Zhejiang 315010; \\ ${ }^{2}$ Ningbo Institute of Life and Health Industry, University of Chinese Academy of Sciences, \\ Ningbo, Zhejiang 315021, P.R. China
}

Received March 5, 2020; Accepted July 24, 2020

DOI: $10.3892 /$ etm.2021.9821

\begin{abstract}
Prostate cancer places a serious health burden on males. The present study aimed to explore the potential prognostic significance and biological function of microRNA (miR)-339-5p in patients with prostate cancer. The expression of miR-339-5p was detected in prostate cancer tissues and cell lines by using reverse transcription-quantitative PCR. Kaplan-Meier survival curves and Cox regression analyses were used to investigate the prognostic significance of miR-339-5p in prostate cancer. The Cell Counting Kit- 8 assay was used to determine the effect of miR-339-5p on prostate cancer cell proliferation. Transwell assays were used to assess the effect of miR-339-5p on cell migration and invasion. The results indicated that the expression of miR-339-5p was downregulated in prostate cancer tissues and cell lines. Downregulation of miR-339-5p was significantly associated with the Gleason score, lymph node metastasis and TNM stage. Patients with high miR-339-5p expression levels had a longer survival time than those with low expression levels. Multivariate Cox regression analysis indicated that miR-339-5p may be an independent prognostic factor for the overall survival of patients with prostate cancer. Overexpression of miR-339-5p inhibited the proliferation, migration and invasion of prostate cancer cells. Taken together, these results indicated that miR-339-5p functions as a suppressor gene in prostate cancer and acts by inhibiting cell proliferation, migration and invasion of prostate cancer cells. miR-339-5p may serve as an independent prognostic biomarker and therapeutic target for the treatment of prostate cancer.
\end{abstract}

\section{Introduction}

Prostate cancer is one of the most common male malignancies worldwide and it has a high incidence in developed

Correspondence to: Dr Yudi Zhu, Department of Urology, Hwa Mei Hospital, University of Chinese Academy of Sciences, 41 Xibei Street, Ningbo, Zhejiang 315010, P.R. China

E-mail: zhuyudi_0403@163.com

Key words: microRNA-339-5p, prostate cancer, prognosis, proliferation, migration, invasion countries (1). The incidence varies among countries due to differences in the coverage of diagnostic procedures [such as prostate-specific antigen (PSA) screening and suspicious digital rectal examination] for prostate cancer detection, which has been identified as a potential influencing factor $(2,3)$. Although the incidence rate of prostate cancer in Eastern Asia, including China, is lower than that in North America and Western Europe, patients in China have a lower overall survival rate than those in developed countries (4-6). For patients with located prostate cancer, radical prostatectomy is the most advanced therapeutic option, but there is still a certain risk of recurrence within 5 years (7). Furthermore, although patients initially diagnosed with prostate cancer at an early stage have a relatively longer overall survival time, numerous patients are diagnosed at an advanced stage and usually have an unsatisfactory prognosis $(8,9)$. Given the increased incidence of prostate cancer and its poor prognosis at advanced stages, the identification of further biomarkers and therapeutic targets is still required.

MicroRNAs (miRNAs/miRs) are a class of small single-stranded non-coding RNAs (approximately 19-25 nucleotides in length) that are able to negatively regulate target gene expression at the posttranscriptional level by binding to the 3'-untranslated region of their target gene (10). Numerous studies have demonstrated that miRNAs are involved in diverse biological processes, including cell proliferation, apoptosis, migration, invasion and differentiation (11-13). Aberrant expression of miRNAs has been detected in various cancer types and may have the potential to be used as diagnostic or prognostic biomarkers and therapeutic targets for cancer treatment (14-16). miR-339-5p was reported to be associated with the diagnosis and prognosis of various cancer types, such as breast cancer (17) and colorectal cancer (18). In prostate cancer, circulating miR-339-5p may serve as a novel noninvasive biomarker for high-grade prostate cancer detection (19). However, the role of miR-339-5p in prostate cancer has remained to be fully elucidated.

In the present study, the expression pattern of miR-339-5p was detected in prostate cancer tissues and cell lines. The prognostic significance of miR-339-5p was assessed in prostate cancer patients. In addition, the effects of miR-339-5p on the biological behaviors of prostate cancer cells were demonstrated. 


\section{Materials and methods}

Patients, tissue specimen collection and follow-up. A total of 122 patients with prostate cancer (age range, 36-85 years; mean age, 60 years) who underwent radical resection surgery between January 2010 and June 2013 at Ningbo No. 2 Hospital (Ningbo, China) were included in the present study. The prostate cancer tissue and matched adjacent normal tissue specimens (at least $1 \mathrm{~cm}$ from the tumor and was confirmed as normal tissues by histopathological examination) were collected during surgery and immediately preserved in liquid nitrogen. The inclusion criteria include: i) All of the specimens were verified by experienced pathologists and ii) none of the patients received any therapy prior to surgery. The exclusion criteria include: i) Recurrent patients with prostate cancer; ii) combined with other types of malignant tumor; iii) patients with severe liver and kidney dysfunction; iv) patients with incomplete clinical information; and v) patients who are not convenient to accept follow-up examinations. The present study was approved by the Ethics Committee of Ningbo No. 2 Hospital (Ningbo, China). All of the patients provided written informed consent. The detailed clinicopathological characteristics of the patients are listed in Table I. The survival information of the patient over a 5-year follow-up was collected for the subsequent survival analysis.

Cell lines and transfection. The normal human prostate epithelial cell line (RWPE-1) and three prostate cancer cell lines (LNCaP, PC-3 and DU145) were purchased from the Cell Bank of the Chinese Academy of Sciences. PC-3 and DU145 cells were incubated in Ham's F12 medium (Hyclone; Cytiva) supplemented with 10\% FBS (Invitrogen; Thermo Fisher Scientific, Inc.). RWPE-1 and LNCaP were cultured in RPMI 1640 medium (Hyclone; Cytiva) supplemented with 10\% FBS (Invitrogen; Thermo Fisher Scientific, Inc.). All cells were incubated in a humidified atmosphere with $5 \% \mathrm{CO}_{2}$ at $37^{\circ} \mathrm{C}$.

For cell transfection, cells were seeded in 6-well plates and cultured until the cells reached $60-80 \%$ confluency within 24 h. miR-339-5p mimics (5'-UCCCUGUCCUCCAGGAGC UCACG-3'), mimics negative control (mimics NC; 5'-UUC UCCGAACGUGUCACGUTT-3'), miR-339-5p inhibitor (5'-CGUGAGCUCCUGGAGGACAGGGA-3') and inhibitor NC (5'-CAGUACUUUUGUGUAGUACAA-3') were synthesized by and purchased from GenePharma. The cells were transfected with $50 \mathrm{nM}$ miR-339-5p mimics, $50 \mathrm{nM}$ mimics NC, $100 \mathrm{nM}$ miR-339-5p inhibitor or $100 \mathrm{nM}$ inhibitor NC using Lipofectamine 2000 (Invitrogen; Thermo Fisher Scientific, Inc.) following the manufacturer's protocol. The cells treated with only the transfection reagents were used as a mock-transfected group.

$R N A$ extraction and reverse transcription-quantitative ( $R T-q)$ $P C R$. Total RNA extraction was performed using TRIzol reagent (Invitrogen; Thermo Fisher Scientific, Inc.). Prior to cDNA synthesis, the quality of the RNA was confirmed by measuring the absorbance at 260 and $280 \mathrm{~nm}$ using a NanoDrop ND-1000 (Peqlab). Subsequently, total RNA was reverse transcribed into cDNA using the Transcriptor First Strand cDNA Synthesis kit (Roche Diagnostics $\mathrm{GmbH}$ ) for $30 \mathrm{~min}$ at $42^{\circ} \mathrm{C}$ and $5 \mathrm{~min}$ at $85^{\circ} \mathrm{C}$ according to the manufacturer's protocols.
For miR-339-5p detection, qPCR was performed on an ABI 7500 system (Applied Biosystems; Thermo Fisher Scientific, Inc.) using SYBR Green (Takara Biotechnology Co., Ltd.) with normalization to U6 expression. The following thermocycling conditions were used for the qPCR: Initial denaturation at $95^{\circ} \mathrm{C}$ for $3 \mathrm{~min}$, followed by 35 cycles of denaturation at $95^{\circ} \mathrm{C}$ for $30 \mathrm{sec}$, annealing at $58^{\circ} \mathrm{C}$ for $15 \mathrm{sec}$ and extension at $72^{\circ} \mathrm{C}$ for $30 \mathrm{sec}$. The following primer pairs were used for the qPCR: miR-339-5p forward, 5'-GCCGAGTCCCTGTCCTCC AGG-3' and reverse, 5'-CTCAACTGGTGTCGTGGA-3' and U6 forward, 5'-GCTTCGGCAGCACATATACTAAAAT-3' and reverse, 5'-CGCTTCACGAATTTGCGTGTCAT-3'. The relative expression levels of miR-339-5p were determined with the $2^{-\Delta \Delta \mathrm{Cq}}$ method (20).

Cell proliferation assay. Cell Counting Kit-8 (CCK-8; Donjindo Molecular Technologies, Inc.) assay was performed to examine the effects of miR-339-5p on the proliferation of prostate cancer cells. The transfected cells were seeded in 96-well plates (Corning, Inc.) at $3 \times 10^{3}$ per well. After culture for $0,24,48$ and $72 \mathrm{~h}, 10 \mu \mathrm{l}$ CCK-8 reagent was added to each well and the cells were incubated for further $2 \mathrm{~h}$. A spectrophotometer (Multiskan MK3; Thermo Fisher Scientific, Inc.) was used to measure the absorbance value at $450 \mathrm{~nm}$.

Cell migration and invasion assays. Cell migration and invasion assays were performed using a Transwell chamber $(8.0-\mu \mathrm{m}$ pores; EMD Millipore). For the invasion assays, the upper chambers were pre-coated with Matrigel (BD Biosciences), while this was not performed for the migration assays. Transfected cells were seeded in the upper chamber in a suspension in serum-free medium at $5 \times 10^{4}$ cells/well. The lower chamber contained $500 \mu \mathrm{l}$ medium with $10 \%$ FBS as a chemoattractant. Following incubation at $37^{\circ} \mathrm{C}$ for $24 \mathrm{~h}$, the cells that remained on the upper side of the membrane were wiped away with a cotton bud and cancer cells that migrated or invaded to the lower chamber were stained with $0.1 \%$ crystal violet for $30 \mathrm{~min}$ at $37^{\circ} \mathrm{C}$. Images of the cells (magnification, $\mathrm{x} 200$ ) were captured and counted using an optical microscope (Olympus Corporation).

Statistical analysis. Statistical analysis was performed using SPSS 20.0 software (IBM Corp.) and GraphPad Prism 5.0 (GraphPad, Inc.). Values are expressed as the mean \pm standard deviation. Statistical comparisons were performed using the $\chi^{2}$ test, paired Student's t-test or one-way analysis of variance followed by Tukey's post-hoc test. The Kaplan-Meier method and the log-rank test were used to estimate the effect of the levels of miR-339-5p on the survival of patients with prostate cancer. Multivariate Cox regression analysis was used to predict the potential risk prognostic factors. $\mathrm{P}<0.05$ was considered to indicate statistical significance.

\section{Results}

miR-339-5p is downregulated in prostate cancer tissues and cell lines. The expression levels of miR-339-5p in prostate cancer tissues and cell lines were detected using RT-qPCR. As presented in Fig. 1A, the expression of miR-339-5p was significantly decreased in tumor tissues as compared with that in their adjacent paired normal tissues $(\mathrm{P}<0.001)$. Furthermore, 
Table I. Association between miR-339-5p expression and clinical characteristics of prostate cancer patients.

\begin{tabular}{|c|c|c|c|c|}
\hline \multirow[b]{2}{*}{ Parameters } & \multirow[b]{2}{*}{ Cases $(n=122)$} & \multicolumn{2}{|c|}{ miR-339-5p expression } & \multirow[b]{2}{*}{ P-value } \\
\hline & & Low $(n=68)$ & High $(n=54)$ & \\
\hline Age (years) & & & & 0.628 \\
\hline$<60$ & 64 & 37 & 27 & \\
\hline$\geq 60$ & 58 & 31 & 27 & \\
\hline PSA (ng/ml) & & & & 0.102 \\
\hline$<10$ & 71 & 44 & 27 & \\
\hline$\geq 10$ & 51 & 24 & 27 & \\
\hline Differentiation & & & & 0.575 \\
\hline Well/moderate & 78 & 42 & 36 & \\
\hline Poor & 44 & 26 & 18 & \\
\hline Gleason score & & & & 0.045 \\
\hline$\leq 7$ & 69 & 33 & 36 & \\
\hline$>7$ & 53 & 35 & 18 & \\
\hline Lymph node metastasis & & & & 0.005 \\
\hline Negative & 71 & 32 & 39 & \\
\hline Positive & 51 & 36 & 15 & \\
\hline TNM stage & & & & 0.002 \\
\hline I-II & 67 & 29 & 38 & \\
\hline III-IV & 55 & 39 & 16 & \\
\hline
\end{tabular}

PSA, prostate-specific antigen; miR, microRNA.
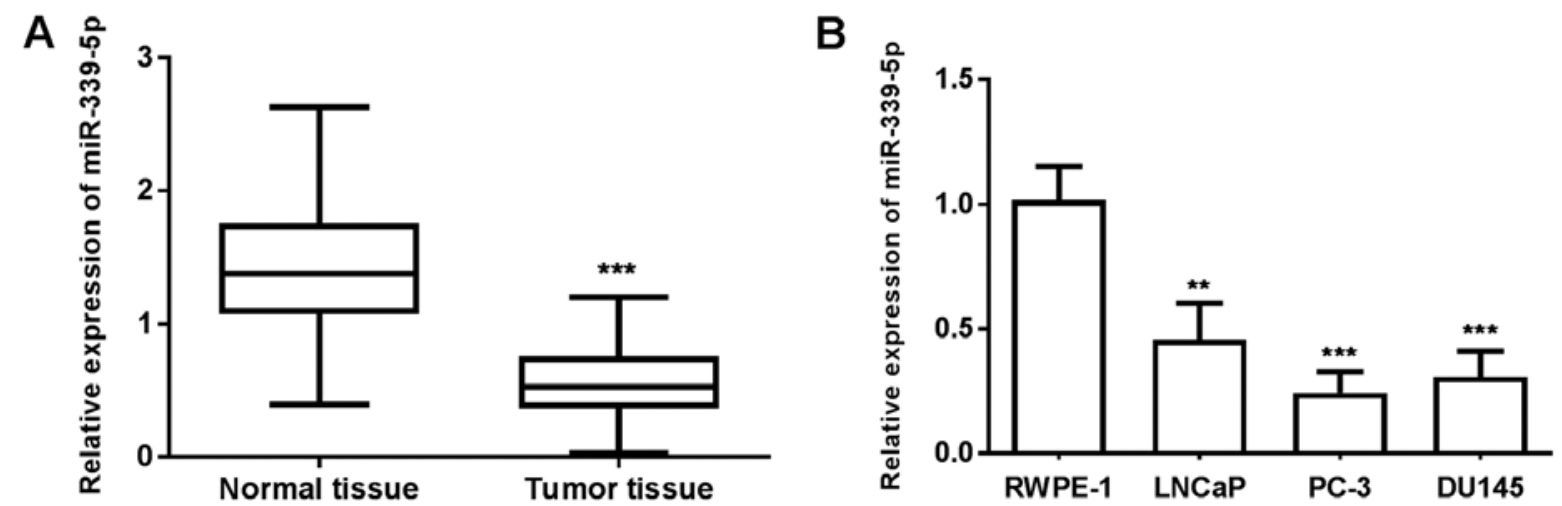

Figure 1. miR-339-5p is decreased in prostate cancer tissues and cell lines. (A) The expression of miR-339-5p in tumor tissues and adjacent normal tissues of prostate cancer patients. (B) The expression of miR-339-5p in prostate cancer cell lines (PC-3, DU145 and LNCaP) and a normal cell line (RWPE-1). ${ }^{* *} \mathrm{P}<0.01$, ${ }^{* * * *} \mathrm{P}<0.001$. miR, microRNA.

the expression of miR-339-5p was downregulated in prostate cancer cell lines as compared with that in the normal cell line RWPE-1 (P<0.01; Fig. 1B).

Association between miR-339-5p expression and clinical characteristics of patients with prostate cancer. Next, the association between miR-339-5p expression and the clinical characteristics of patients with prostate cancer was further analyzed. The patients were classified into a low miR-339-5p expression group $(n=68)$ and a high miR-339-5p expression group $(n=54)$, using the mean value of miR-339-5p expression as the cut-off value. As indicated in Table I, the expression of miR-339-5p was significantly associated with the
Gleason score $(\mathrm{P}=0.045)$, lymph node metastasis $(\mathrm{P}=0.005)$ and TNM stage $(\mathrm{P}=0.002)$. By contrast, no significant association was obtained between miR-339-5p expression and any other factors assessed, including patient age, PSA levels and degree of differentiation $(\mathrm{P}>0.05)$.

Association of miR-339-5p with the prognosis of patients with prostate cancer. Kaplan-Meier survival curve and multivariate Cox regression analyses of the expression levels of miR-339-5p and overall survival information of patients with prostate cancer were used to explore the prognostic value of miR-339-5p in prostate cancer. The results indicated that patients with high expression levels of miR-339-5p had longer 
Table II. Multivariate Cox regression analysis for miR-339-5p in patients with prostate cancer.

\begin{tabular}{lccr}
\hline & \multicolumn{2}{c}{ Multivariate analysis } \\
\cline { 2 - 4 } Characteristics & HR & $95 \% \mathrm{CI}$ & P-value \\
\hline miR-339-5p & 2.848 & $1.156-7.016$ & 0.023 \\
Age & 1.256 & $0.607-2.599$ & 0.539 \\
PSA & 0.572 & $0.273-1.197$ & 0.138 \\
Differentiation & 2.126 & $0.780-5.789$ & 0.140 \\
Gleason score & 0.559 & $0.266-1.177$ & 0.126 \\
Lymph node metastasis & 2.392 & $0.994-5.755$ & 0.051 \\
TNM stage & 2.656 & $1.112-6.345$ & 0.028 \\
\hline
\end{tabular}

PSA, prostate-specific antigen; miR, microRNA; HR, hazard ratio.

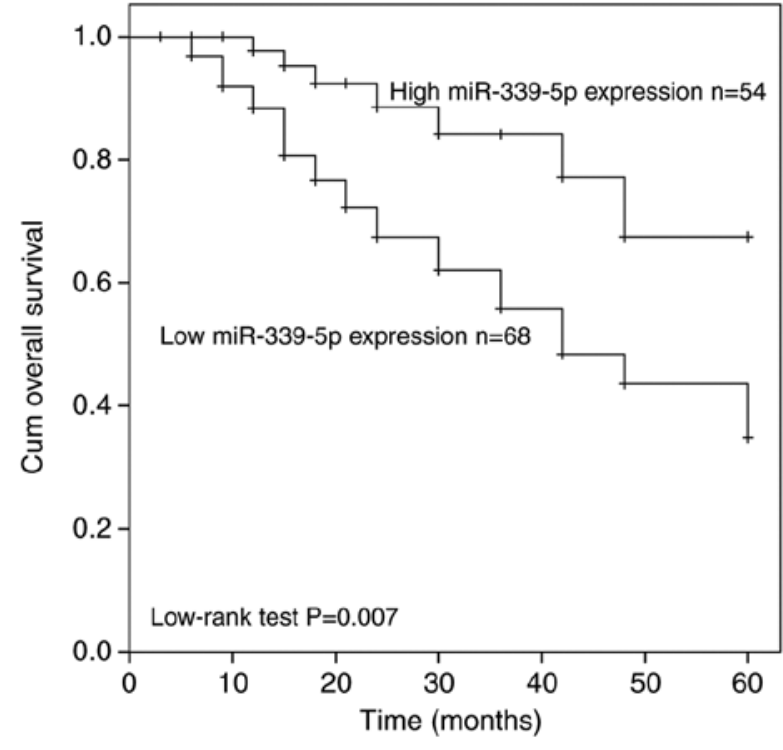

Figure 2. Kaplan-Meier survival analysis reveals that prostate cancer patients with low expression of miR-339-5p have poor overall survival rates. Log-rank test $\mathrm{P}=0.007 .+$, censored data-points. miR, microRNA; Cum, cumulative.

survival times compared with those with low expression levels (log-rank $\mathrm{P}=0.007$; Fig. 2). In addition, all factors were included in multivariate Cox regression analysis and the results indicated that the TNM stage [hazard ratio $(\mathrm{HR})=2.656,95 \% \mathrm{CI}$ : 1.112-6.345, $\mathrm{P}=0.028$ ] and $\mathrm{miR}-339-5 \mathrm{p}$ expression $(\mathrm{HR}=2.848$, 95\% CI: 1.156-7.016, $\mathrm{P}=0.023$ ) were independent prognostic factors for overall survival (Table II).

Effects of miR-339-5p on cell proliferation, migration and invasion. To determine the biological roles of miR-339-5p in prostate cancer, the effects of miR-339-5p expression on prostate cancer cell proliferation, migration and invasion were investigated using transfected PC-3 and DU145 cells, which were determined to have a relatively lower miR-339-5p expression. The efficiency of overexpression and knockdown was confirmed by RT-qPCR. The results in Fig. 3A indicated that the transfection of miR-339-5p mimics significantly increased the expression of miR-339-5p, while the transfection of miR-339-5p inhibitor markedly decreased the expression of miR-339-5p $(\mathrm{P}<0.001)$. The CCK-8 assay was then used to explore the effect of miR-339-5p on cell proliferation. The results indicated that the proliferation rate of miR-339-5p-overexpressing cells was significantly decreased, while that of miR-339-5p-knockdown cells was significantly increased as compared with mock and corresponding NC groups $(\mathrm{P}<0.05$; Fig. 3B). Transwell migration and invasion assays indicated that overexpression of miR-339-5p by transfection of miR-339-5p mimics significantly inhibited the cell migration and invasion of PC-3 and DU145 cells, while knockdown of miR-339-5p by miR-339-5p inhibitor promoted cell migration and invasion $(\mathrm{P}<0.001$; Fig. $4 \mathrm{~A}$ and $\mathrm{B})$. Representative images for the migration and invasion assays are provided in Fig. S1.

\section{Discussion}

Prostate cancer remains a significant health burden in males worldwide. Despite the progressive advances in therapeutic approaches and the fact that most prostate cancer patients do not die of the primary tumor, a number of patients eventually experience recurrence, leading to accelerated disease progression and death (21). Distant metastasis, particularly bone metastasis, is a frequent characteristic of patients who die of prostate cancer $(22,23)$. In recent decades, an increasing number of molecular markers, including miRNAs, have been studied as potential biomarkers of disease formation and progression in various cancer types (24). For instance, miR-206 and miR-104 are aberrantly expressed in breast cancer and may serve as an important indicator of the prognosis of affected patients (25). miR-29a was reported to be expressed at low levels in cervical cancer and to have a role of suppressing migration and invasion by targeting sirtuin 1 , and downregulation of miR-29a was associated with poor outcome in patients cervical cancer (26).

Predicting patient prognosis is an important aspect of clinical prostate cancer treatment. Therefore, several studies have been established to identify differential miRNA expression patterns in prostate cancer tissue for predicting the risk of developing aggressive prostate cancer $(27,28)$. Numerous studies have demonstrated that miR-339-5p is aberrantly expressed and associated with the prognosis of 

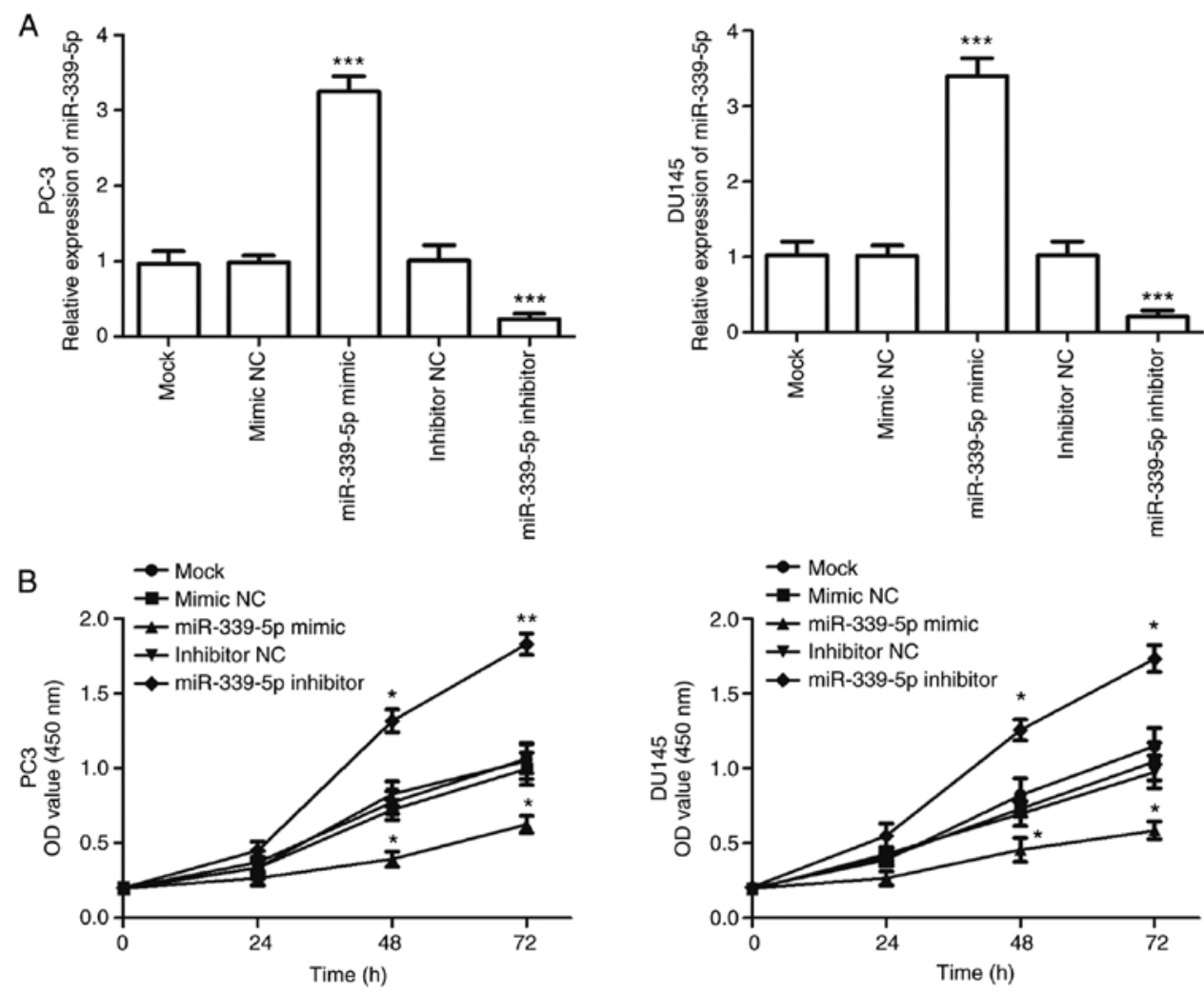

Figure 3. Effects of miR-339-5p on the proliferation of prostate cancer cell lines (PC-3 and DU145). (A) The expression of miR-339-5p was significantly increased by the miR-339-5p mimics but was suppressed by the miR-339-5p inhibitor, compared to the mock and corresponding NC group. (B) Overexpression of miR-339-5p suppressed cell proliferation, while downregulation of miR-339-5p promoted cell proliferation, as compared with that in the mock and corresponding NC group. ${ }^{*} \mathrm{P}<0.05,{ }^{* *} \mathrm{P}<0.01,{ }^{* * * *} \mathrm{P}<0.001$. miR, microRNA; NC, negative control; OD, optical density.
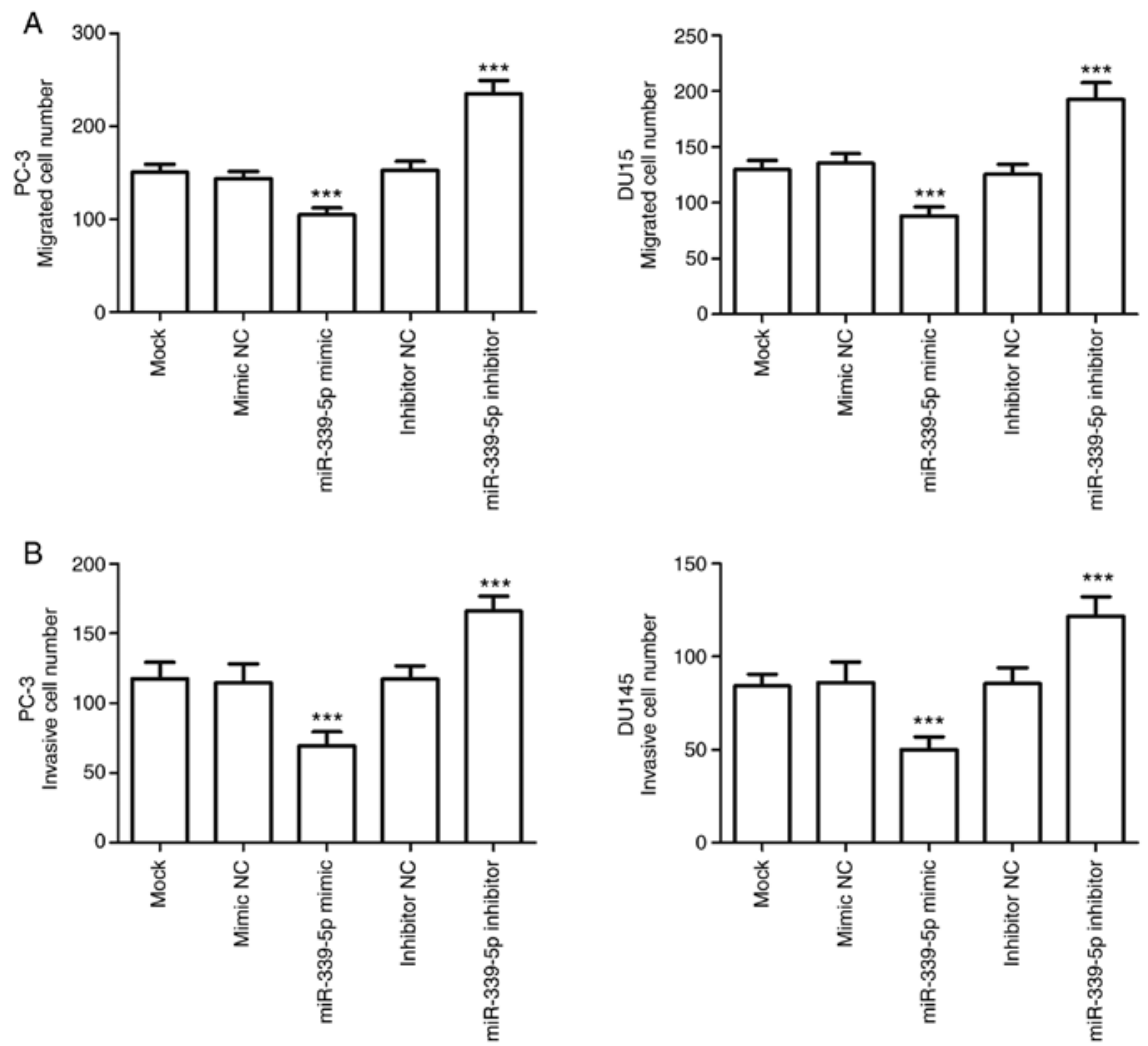

Figure 4. Effects of miR-339-5p on the migration and invasion of prostate cancer cell lines (PC-3 and DU145). (A) Upregulation of miR-339-5p inhibited prostate cancer cell migration, while downregulation of miR-339-5p promoted cell migration. (B) Cell invasive capacities were inhibited by the overexpression of miR-339-5p but were promoted by the inhibition of miR-339-5p in prostate cancer cells, as compared with those in the mock and corresponding NC group. ${ }^{* * * * *} \mathrm{P}<0.001$. miR, microRNA; NC, negative control. 
several types of cancer $(17,29)$. For instance, miR-339-5p is downregulated in hepatocellular carcinoma, suggesting that it has a tumor suppressor role, and it may serve as a prognostic marker and molecular therapeutic target in this type of malignancy (30). To investigate the clinical role of miR-339-5p in prostate cancer, its expression patterns in tissues and its prognostic significance were investigated in patients with prostate cancer in the present study. First, the expression of miR-339-5p was detected in prostate cancer tissues and cell lines. The results indicated that miR-339-5p was significantly downregulated in surgically excised prostate cancer tissues and cell lines compared with normal controls. Next, the association between miR-339-5p expression and the clinical characteristics of prostate cancer patients was analyzed. The expression of miR-339-5p was significantly associated with lymph node metastasis and TNM stage. These results suggested that miR-339-5p has a tumor suppressor role in prostate cancer and its downregulation is involved in the progression of this malignancy. Furthermore, the prognostic significance of miR-339-5p in prostate cancer was investigated using Kaplan-Meier curve and Cox regression analyses. The results indicated that low expression of miR-339-5p was associated with a shorter overall survival rate in patients with prostate cancer and that miR-339-5p expression was an independent prognostic factor in affected patients.

Previous studies confirmed that miR-339-5p has the role of a tumor suppressor in various cancer types (31-33). For instance, miR-339-5p functions as a tumor suppressor and inhibits colorectal cancer cell growth and metastasis by targeting phosphatases of regenerating liver-1, suggesting that miR-339-5p may be a novel potential therapeutic target for colorectal cancer (34). In the present study, to explore the biological function of miR-339-5p in the progression of prostate cancer, loss- and gain-of-function experiments were performed to investigate the effect of miR-339-5p on the proliferation, migration and invasion of prostate cancer cell lines. Regarding cellular functions, overexpression of miR-339-5p suppressed tumor cell proliferation, migration and invasion in vitro. These results indicate that miR-339-5p expression may be involved in the development and progression of prostate cancer. Numerous studies have indicated that miR-339-5p has an important role in the development and tumorigenesis of several types of cancers by regulating the expression of target genes, including Cdc25A (35), BCL6 (36) and SOX4 (37). In acute myeloid leukemia, miR-339-5p also functions as a tumor suppressor and inhibits cell proliferation by targeting SOX4 (37). SOX4 has been reported to be upregulated in different cancer types and act as an oncogene through promoting tumor progression $(38,39)$. A previous study has reported that SOX4 was upregulated and involved in the progression of prostate cancer, and may serve as a potential therapeutic target in prostate cancer (40). Therefore, it may be speculated that miR-339-5p may also suppress prostate cancer cell proliferation, migration and invasion by targeting SOX4. However, whether miR-339-5p serves as a tumor suppressor in prostate cancer by targeting SOX4 or other target genes and the precise molecular mechanisms of miR-339-5p still require to be confirmed in further studies. In addition, the detailed function of miR-339-5p on cell proliferation and growth, as well as metastasis, will be examined in future molecular mechanistic studies.

Taken together, the present study demonstrated that miR-339-5p is downregulated in prostate cancer tissues and cell lines and suppresses prostate cancer cell proliferation, migration and invasion in vitro, suggesting that miR-339-5p may be an independent prognostic biomarker and therapeutic target for prostate cancer.

\section{Acknowledgements}

Not applicable.

\section{Funding}

No funding was received.

\section{Availability of data and materials}

The datasets used and/or analyzed during the current study are available from the corresponding author on reasonable request.

\section{Authors' contributions}

HP and YZ designed the study. HP, XR, WW and SS performed the experiments. HP and YZ drafted and revised the manuscript. All authors read and approved the final manuscript.

\section{Ethics approval and consent to participate}

The present study was approved by the Ethics Committee of Ningbo No. 2 Hospital (Ningbo, China). All of the patients provided written informed consent.

\section{Patient consent for publication}

Not applicable.

\section{Competing interests}

The authors declare that they have no competing interests.

\section{References}

1. Hoffman RM, Meisner AL, Barry M, Shah SK, Zeliadt SB and Wiggins CL: Trends in United States prostate cancer incidence rates by age and stage, 1995-2012. Cancer Epidemiol Biomarkers Prev 25: 259-263, 2016.

2. Hayes JH and Barry MJ: Screening for prostate cancer with the prostate-specific antigen test: A review of current evidence. JAMA 311: 1143-1149, 2014.

3. Winter A, Sirri E, Jansen L, Wawroschek F, Kieschke J, Castro FA, Krilaviciute A, Holleczek B, Emrich K, Waldmann A, et al: Comparison of prostate cancer survival in Germany and the USA: Can differences be attributed to differences in stage distributions? BJU Int 119: 550-559, 2017.

4. Wong MC, Goggins WB, Wang HH, Fung FD, Leung C, Wong SY, Ng CF and Sung JJ: Global incidence and mortality for prostate cancer: Analysis of temporal patterns and trends in 36 countries. Eur Urol 70: 862-874, 2016.

5. Reulen RC, de Vogel S, Zhong W, Zhong Z, Xie LP, Hu Z, Deng Y, Yang K, Liang Y, Zeng X, et al: Physical activity and risk of prostate and bladder cancer in China: The South and East China case-control study on prostate and bladder cancer. PLoS One 12: e0178613, 2017. 
6. Qi JL, Wang LJ, Zhou MG, Liu YN, Liu JM, Liu SW, Zeng XY and Yin P: Disease burden of prostate cancer among men in China, from 1990 to 2013. Zhonghua Liu Xing Bing Xue Za Zhi 37: 778-782, 2016 (In Chinese).

7. Lin C, Bai S, Du T, Lai Y, Chen X, Peng S, Ma X, Wu W, Guo $\mathrm{Z}$ and Huang H: Polo-like kinase 3 is associated with poor prognosis and regulates proliferation and metastasis in prostate cancer. Cancer Manag Res 11: 1517-1524, 2019.

8. Downing A, Wright P, Hounsome L, Selby P, Wilding S, Watson E, Wagland R, Kind P, Donnelly DW, Butcher $\mathrm{H}$, et al Quality of life in men living with advanced and localised prostate cancer in the UK: A population-based study. Lancet Oncol 20: 436-447, 2019.

9. Park SH, Eber MR and Shiozawa Y: Models of prostate cancer bone metastasis. Methods Mol Biol 1914: 295-308, 2019.

10. Liu B, Li J and Cairns MJ: Identifying miRNAs, targets and functions. Brief Bioinform 15: 1-19, 2014.

11. Zhang Q, Zhang K, Zhang C, Ge H, Yin Y, Feng H and Hu R MicroRNAs as big regulators of neural stem/progenitor cell proliferation, differentiation and migration: A potential treatment for stroke. Curr Pharm Des 23: 2252-2257, 2017.

12. Liu H, Cao B, Zhao Y, Liang $\mathrm{H}$ and Liu X: Upregulated miR-221/222 promotes cell proliferation and invasion and is associated with invasive features in retinoblastoma. Cancer Biomark 22: 621-629, 2018.

13. Peng P, Chen T, Wang Q, Zhang Y, Zheng F, Huang S, Tang Y, Yang C, Ding W, Ren D, et al: Decreased miR-218-5p levels as a serum biomarker in bone metastasis of prostate cancer. Oncol Res Treat 42: 165-185, 2019.

14. Nagahama Y and Fukui T: Dementia with Lewy bodies presenting as frontotemporal dementia phenotype. Psychogeriatrics 19 : 505-509, 2019.

15. Moya L, Meijer J, Schubert S, Matin F and Batra J: Assessment of miR-98-5p, miR-152-3p, miR-326 and miR-4289 expression as biomarker for prostate cancer diagnosis. Int J Mol Sci 20: 1154, 2019.

16. Malla RR, Kumari S, Gavara MM, Badana AK, Gugalavath S, Kumar DKG and Rokkam P: A perspective on the diagnostics, prognostics, and therapeutics of microRNAs of triple-negative breast cancer. Biophys Rev 11: 227-234, 2019.

17. Bertoli G, Cava C and Castiglioni I: MicroRNAs: New biomarkers for diagnosis, prognosis, therapy prediction and therapeutic tools for breast cancer. Theranostics 5: 1122-1143, 2015.

18. Yang L, Belaguli N and Berger DH: MicroRNA and colorectal cancer. World J Surg 33: 638-646, 2009.

19. Foj L and Filella X: Identification of potential miRNAs biomarkers for high-grade prostate cancer by integrated bioinformatics analysis. Pathol Oncol Res 25: 1445-1456, 2019.

20. Livak KJ and Schmittgen TD: Analysis of relative gene expression data using real-time quantitative PCR and the 2(-Delta Delta C(T)) method. Methods 25: 402-408, 2001.

21. Quiroz-Munoz M, Izadmehr S, Arumugam D, Wong B Kirschenbaum A and Levine AC: Mechanisms of osteoblastic bone metastasis in prostate cancer: Role of prostatic acid phosphatase. J Endocr Soc 3: 655-664, 2019.

22. Loberg RD, Logothetis CJ, Keller ET and Pienta KJ: Pathogenesis and treatment of prostate cancer bone metastases: Targeting the lethal phenotype. J Clin Oncol 23: 8232-8241, 2005.

23. Kelly SP, Anderson WF, Rosenberg PS and Cook MB: Past, current, and future incidence rates and burden of metastatic prostate cancer in the United States. Eur Urol Focus 4: 121-127, 2018.
24. Costa-Pinheiro P, Montezuma D, Henrique R and Jeronimo C: Diagnostic and prognostic epigenetic biomarkers in cancer. Epigenomics 7: 1003-1015, 2015.

25. Quan Y, Huang X and Quan X: Expression of miRNA-206 and miRNA-145 in breast cancer and correlation with prognosis. Oncol Lett 16: 6638-6642, 2018

26. Nan P, Niu Y, Wang X and Li Q: MiR-29a function as tumor suppressor in cervical cancer by targeting SIRT1 and predict patient prognosis. Onco Targets Ther 12: 6917-6925, 2019.

27. Casanova-Salas I, Rubio-Briones J, Calatrava A, Mancarella C, Masiá E, Casanova J, Fernández-Serra A, Rubio L, Ramírez-Backhaus M, Armiñán A, et al: Identification of miR-187 and miR-182 as biomarkers of early diagnosis and prognosis in patients with prostate cancer treated with radical prostatectomy. J Urol 192: 252-259, 2014.

28. Goto Y,Kurozumi A, Arai T, Nohata N, Kojima S, Okato A, Kato M, Yamazaki K, Ishida Y, Naya Y, et al: Impact of novel miR-145-3p regulatory networks on survival in patients with castration-resistant prostate cancer. Br J Cancer 117: 409-420, 2017.

29. Sun Y, Mei $\mathrm{H}$, Xu C, Tang $\mathrm{H}$ and Wei W: Circulating microRNA-339-5p and -21 in plasma as an early detection predictors of lung adenocarcinoma. Pathol Res Pract 214: 119-125, 2018.

30. Wang YL, Chen CM, Wang XM and Wang L: Effects of miR-339-5p on invasion and prognosis of hepatocellular carcinoma. Clin Res Hepatol Gastroenterol 40: 51-56, 2016.

31. Gan CZ, Li G, Luo QS and Li HM: MiR-339-5p downregulation contributes to Taxol resistance in small-cell lung cancer by targeting $\alpha 1,2$-fucosyltransferase 1.IUBMB Life 69: 841-849, 2017.

32. Shan W, Li J, Bai Y and Lu X: MiR-339-5p inhibits migration and invasion in ovarian cancer cell lines by targeting NACC1 and BCL6. Tumour Biol 37: 5203-5211, 2016.

33. Jansson MD, Damas ND, Lees M, Jacobsen A and Lund AH: MiR-339-5p regulates the p53 tumor-suppressor pathway by targeting MDM2. Oncogene 34: 1908-1918, 2015.

34. Zhou C, Liu G, Wang L, Lu Y, Yuan L, Zheng L, Chen F, Peng F and $\mathrm{Li} \mathrm{X}$ : MiR-339-5p regulates the growth, colony formation and metastasis of colorectal cancer cells by targeting PRL-1. PLoS One 8: e63142, 2013.

35. Luo A, Zhou X, Shi X, Zhao Y, Men Y, Chang X, Chen H, Ding F, Li Y, Su D, et al: Exosome-derived miR-339-5p mediates radiosensitivity by targeting Cdc25A in locally advanced esophageal squamous cell carcinoma. Oncogene 38: 4990-5006, 2019.

36. Li P, Liu H, Li Y, Wang Y, Zhao L and Wang H: MiR-339-5p inhibits lung adenocarcinoma invasion and migration by directly targeting BCL6. Oncol Lett 16: 5785-5790, 2018.

37. Sun X, Liu H, Li T and Qin L: MicroRNA-339-5p inhibits cell proliferation of acute myeloid leukaemia by directly targeting SOX4. Mol Med Rep 18: 5261-5269, 2018.

38. Grimm D, Bauer J, Wise P, Krüger M, Simonsen U, Wehland M, Infanger $M$ and Corydon TJ: The role of SOX family members in solid tumours and metastasis. Semin Cancer Biol S1044-579X(18)30141-X, 2019 (Epub ahead of print).

39. Moran JD, Kim HH, Li Z and Moreno CS: SOX4 regulates invasion of bladder cancer cells via repression of WNT5a. Int J Oncol 55: 359-370, 2019.

40. Liu Y, Zeng S, Jiang X, Lai D and Su Z: SOX4 induces tumor invasion by targeting EMT-related pathway in prostate cancer. Tumour Biol 39: 1010428317694539, 2017. 